\title{
THE INFLUENCE OF VISIBILITY CONDITIONS IN HORIZONTAL ROAD CURVES ON THE EFFICIENCY OF NOISE PROTECTION BARRIERS
}

Tamara Džambas, Assistant, MCE, University of Zagreb, Faculty of Civil Engineering, Fra Andrije Kačića-Miošića 26, 10000 Zagreb, Croatia, e-mail: tdzambas@grad.hr

Saša Ahac, Sc. novice, MCE, University of Zagreb, Faculty of Civil Engineering, Fra Andrije Kačića-Miošića 26, 10000 Zagreb, Croatia, e-mail: $\underline{\text { sahac@grad.hr }}$

Vesna Dragčević, Prof., PhdCE, University of Zagreb, Faculty of Civil Engineering, Fra Andrije Kačića-Miošića 26, 10000 Zagreb, Croatia, e-mail: vesnad@grad.hr

\section{Abstract}

Ensuring sufficient visibility on planned roads by sight distance testing is an integral part of every project, but problems with visibility can emerge when noise barriers are erected on existing roads. Namely, in order to provide sufficient noise protection, high noise barriers are often placed at minimum distance from the carriageway edge, and additional visibility testing in most cases is not carried out.

Research described in this paper consists of stopping sight distance tests conducted by means of specialized road design software MX Road, and noise barrier optimization conducted by means of specialized noise prediction software LimA using static noise calculation method RLS 90. The aim of this research is to establish whether the required stopping sight distance on road sections where minimum design parameters are applied can be achieved if the noise barrier is placed at minimum distance from the carriageway edge, and to establish whether the optimized dimensions of planned noise protection barrier will change if the barrier is placed on larger distance from the noise source, which is, in this case, the existing road.

Keywords: visibility, horizontal curves, noise protection barriers

\section{INTRODUCTION}

Considering the fact that drivers receive $95 \%$ of all information from the environment by sense of sight and that the lack of visibility is direct or indirect cause of almost $40 \%$ of all traffic accidents on suburban roads [1], it can be stated with certainty that a significant role in road design belongs to sight distance testing. In this paper stopping sight distance on horizontal curves was observed. This important safety factor is ensured by removing all obstacles from visibility field on the inside of a horizontal curve; traffic noise protection 
barriers are no exception. Barriers are often placed at minimum distance from carriageway edge of existing roads while additional visibility testing in most cases is not carried out.

In order to increase road traffic safety with simultaneous implementation of noise protection, necessary to improve the life quality of residents in the vicinity of roads, tests described in this paper were carried out. Sight distance testing was conducted by specialized road design software MX Road, and barrier optimization by specialized noise prediction software LimA. Tests were performed on eight road models with different curve deflection angles - from $20^{\circ}$ to $90^{\circ}$.

\section{VISIBILITY CONDITIONS IN HORIZONTAL ROAD CURVES}

Term "visibility" implies a certain area in which there are no obstructions of the driver's line of sight, [2]. Visibility is determined by infliction of horizontal and vertical alignment, namely minimum radius of horizontal and vertical curves. In engineering practice there are two different lengths of visibility: stopping sight distance and overtaking sight distance, [3]. It is considered that ensuring of stopping sight distance is basic factor of road traffic safety.

According to [3], stopping sight distance is equal to the vehicles stopping distance, and therefore it must be ensured at all road sections, horizontally and vertically, for both driving directions. This research is focused only on visibility conditions in horizontal road curves.

Elements of stopping sight distance are sight distance length $\left(\mathrm{P}_{\mathrm{z}}\right)$, sight distance width (b), and horizontal curve radius $\left(\mathrm{R}_{\min }\right)$, which is in direct correlation with driving speed $\mathrm{V}_{\mathrm{r}}$. Elements of stopping sight distance are shown in Figure 1. Sight distance length is defined as a tendon that connects the point of driver's eye position in vehicle and fixed obstacle which driver must perceive. Driver's eye is placed at the height of 1 meter above road surface, and at the distance of $1.5 \mathrm{~m}$ from the edge of the driving lane ("driving line"), [3]. Fixed obstacle is also placed in driving line, at height of $20-25 \mathrm{~cm}$, depending on driving speed, [3]. Sight distance width is determined at maximum distance between tendon and driving line, and can be calculated by equation, [3]:

$$
b=\frac{P_{z}^{2}}{8 R}[\mathrm{~m}]
$$


Values of stopping sight distance length and width, depending on driving speed $\mathrm{V}_{\mathrm{r}}$, are given in Table 1, [3]. These values refer only for roads with longitudinal grade $0 \%$.

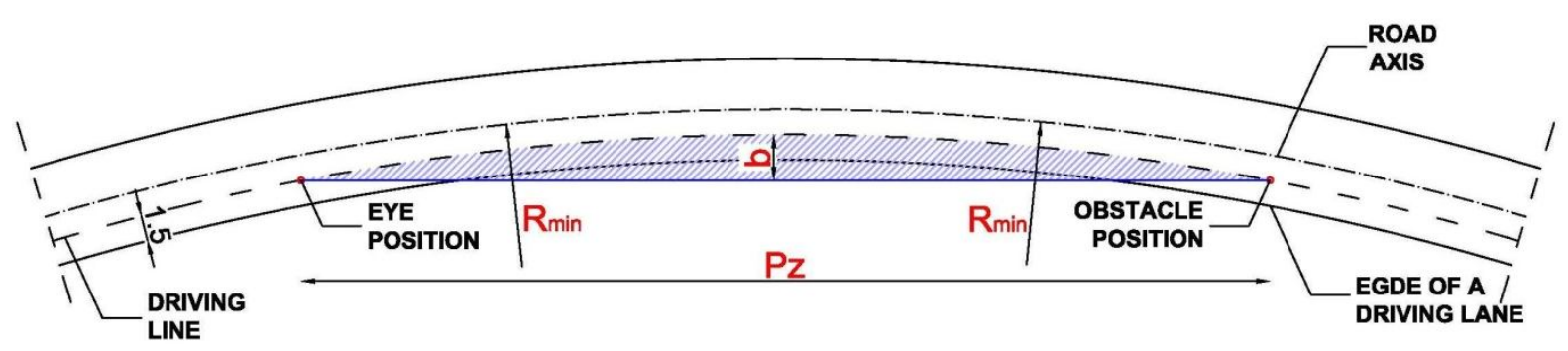

Figure 1. Elements of horizontal stopping sight distance

Table 1. Values of sight distance elements for driving speed $30-120 \mathrm{~km} / \mathrm{h}$

\begin{tabular}{|l|c|c|c|c|c|c|c|c|c|c|}
\hline $\mathbf{V}_{\mathbf{r}}[\mathbf{k m} / \mathbf{h}]$ & $\mathbf{3 0}$ & $\mathbf{4 0}$ & $\mathbf{5 0}$ & $\mathbf{6 0}$ & $\mathbf{7 0}$ & $\mathbf{8 0}$ & $\mathbf{9 0}$ & $\mathbf{1 0 0}$ & $\mathbf{1 1 0}$ & $\mathbf{1 2 0}$ \\
\hline $\mathbf{R}_{\mathbf{m i n}}[\mathbf{m}]$ & 25 & 45 & 75 & 120 & 175 & 250 & 350 & 450 & 600 & 750 \\
\hline $\mathbf{P}_{\mathbf{z}}[\mathbf{m}]$ & 25 & 35 & 50 & 70 & 90 & 120 & 150 & 190 & 230 & 280 \\
\hline $\mathbf{b}[\mathbf{m}]$ & 2.9 & 3.6 & 4.3 & 5.1 & 6.0 & 7.1 & 8.3 & 9.9 & 11.3 & 13.3 \\
\hline
\end{tabular}

Required horizontal stopping sight distance can be achieved by removing all obstacles from visibility field - by clearing of vegetation, banning of construction near the road, additional excavation or placing the supporting wall. If there are road sections where sight distance cannot be achieved by these procedures, driving speed must be limited to values where sight distance is ensured (Table 1).

Ensuring sufficient visibility on planned roads by sight distance testing is an integral part of every project, but problems with visibility can emerge when noise barriers, as the most prevalent measures of noise protection, are erected on existing roads.

Sound barriers are purpose made obstacles placed in areas that must be protected from traffic (or any kind of) noise. They can be of various types, design, materials and acoustic performances, depending on required level of noise protection.

Traffic noise protection barriers are placed between source of the noise (road) and the receiver (protected object). For the optimal performance of barrier it is necessary to place it as close as possible to the noise source. This can be 
explained as follows. Straight expansion path of sound wave that spreads from noise source to receiver is changed by placing barrier between them (Fig. 2). Depending on barrier characteristics, some of the sound waves are reflected, some are absorbed, part is transmitted, and at the barrier top diffraction occurs. With increase of the diffraction angle (angle between direct and diffracted sound wave shown at Figure 2) i.e. decrease of the distance from noise source, the energy of the diffracted wave is also decreased, and barrier is more efficient.

This research refers to the examination of whether barrier shifting from minimum distance from carriageway edge for amount of required sight distance width has influence on its efficiency apropos optimized dimensions.
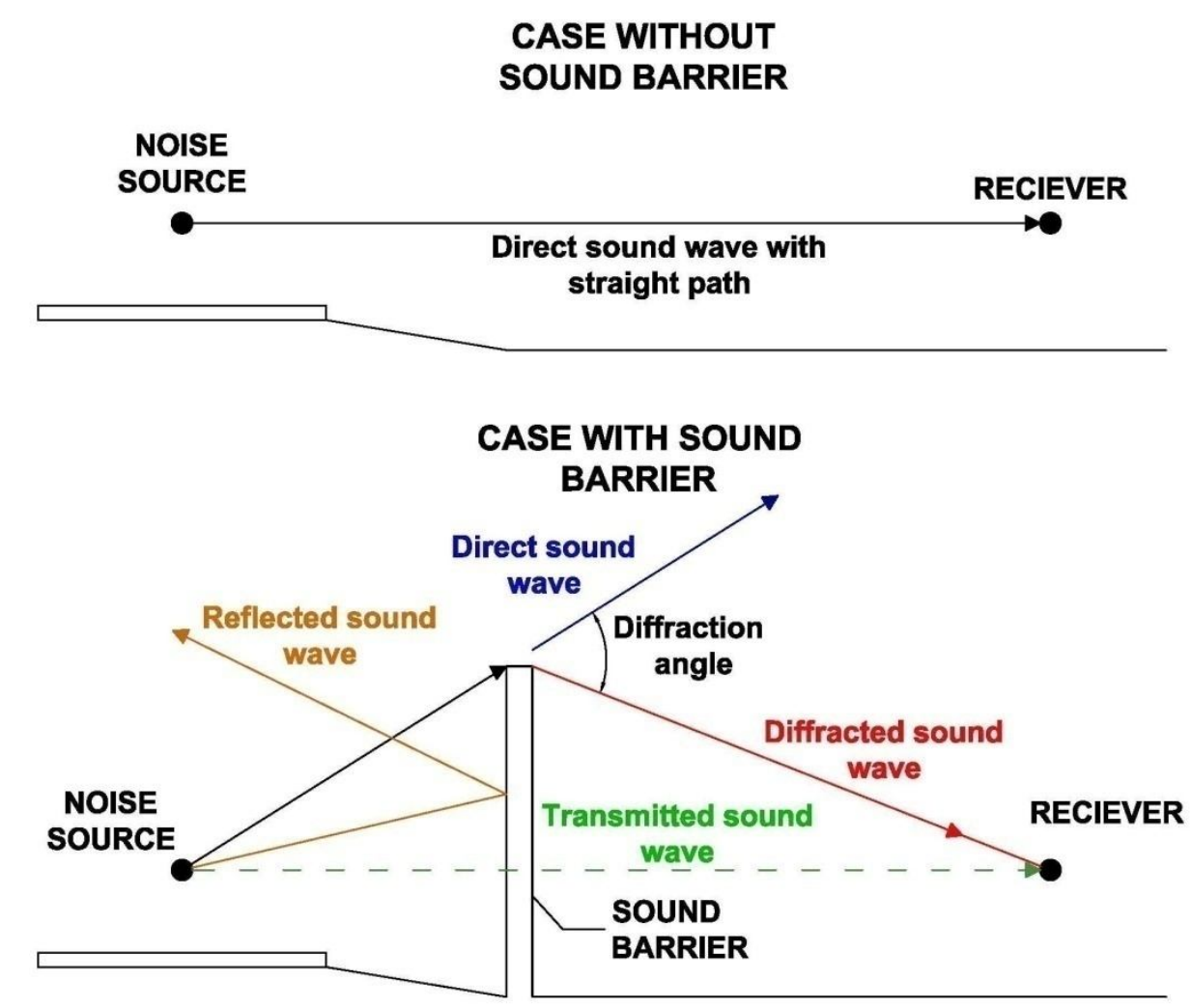

Figure 2. Change of sound wave direction caused by barrier [4]

\section{VISIBILITY TESTING}

Stopping sight distance testing was conducted by specialized road design software MX Road, using the analysis module „Through Visibility“. This module is utilised to assess visibility along a road using plan, profile and perspective views simultaneously. In accordance with input data for driver's eye position, target position, required stopping sight distance length and obstacle 
beside the road, MX Road determines cross sections with unfulfilled sight distance.

\subsection{Road models for visibility testing}

Visibility tests were performed on eight horizontal curves with the same (minimum) radii, but different curve deflection angles - from $20^{\circ}$ to $90^{\circ}$, with angle interval of $10^{\circ}$ (Fig. 3). In order to simplify the road models, surrounding terrain was designed as flat surface, and roads were situated on 2 meter high embankment. Design speed of $80 \mathrm{~km} / \mathrm{h}$ was presumed, which resulted in required sight distance length of 120 meters, required minimum radius of $250 \mathrm{~m}$, transition length of $60 \mathrm{~m}$, and cross section elements as shown in Figure 4. All analysed road models have longitudinal grade of $0 \%$, and cross section grade of $2.5 \%$ in straight sections i.e. $7 \%$ in curve sections.
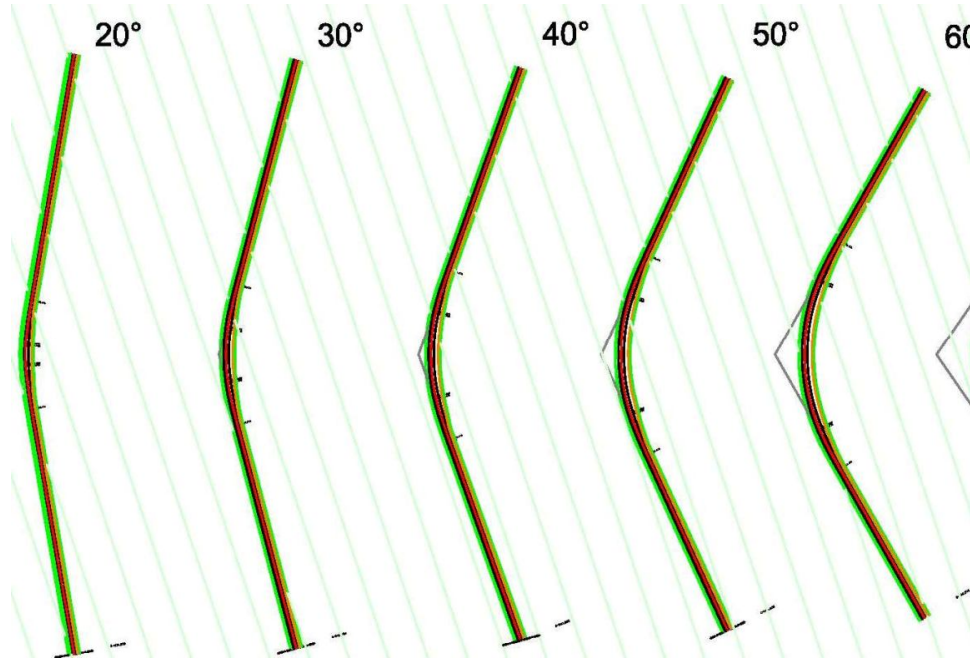

$60^{\circ}$

$70^{\circ} \quad 80^{\circ}$

$90^{\circ}$

Figure 3. Visibility testing models with various curve deflection angles

Five meters high noise barrier located at minimum required distance of 1.5 meters from the carriageway edge at the inside of a road curve is taken as input parameter for visibility field restriction. Minimum distance from carriageway edge is required to provide space for placing the road guard rails and barrier maintenance. Considering the above, visibility tests are performed only for ride through the inner side of curve. 


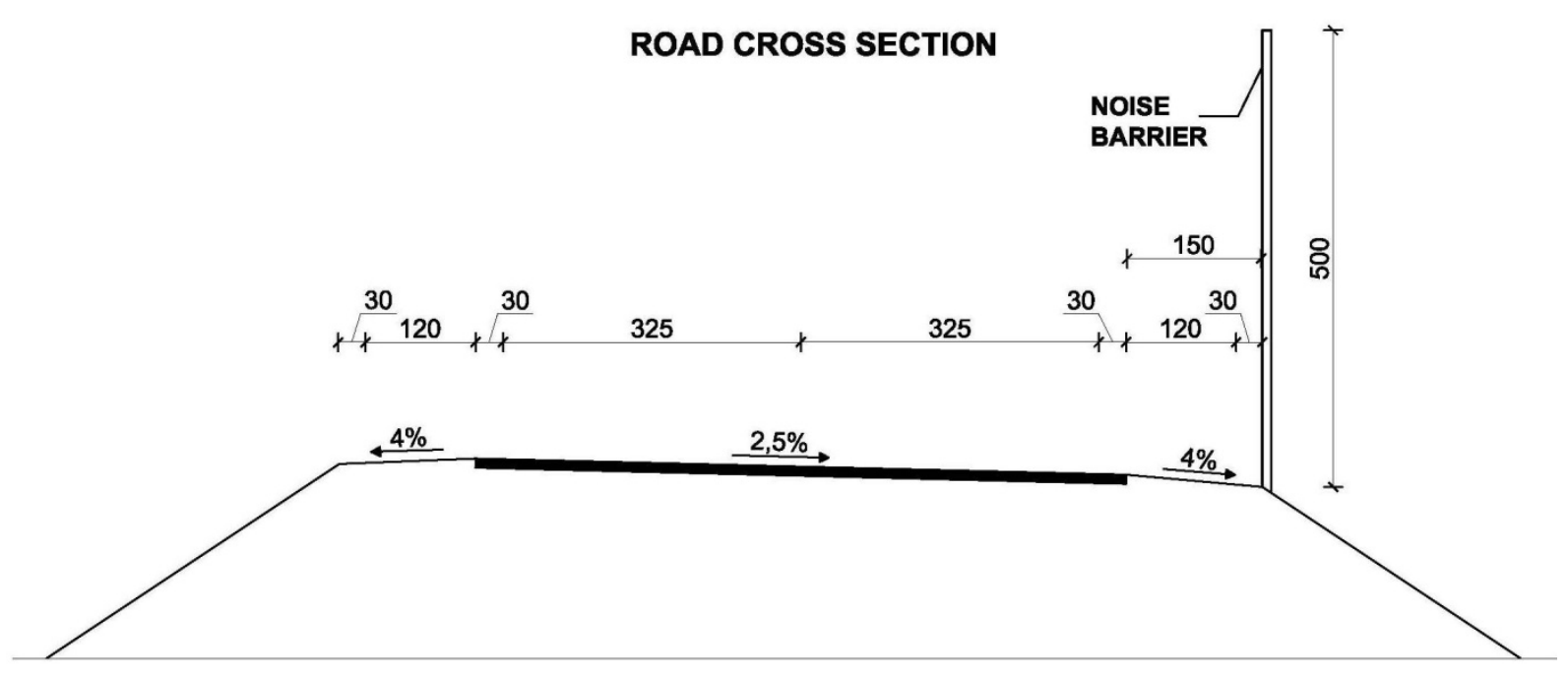

Figure 4. Cross section of visibility testing models

\subsection{Visibility test results}

MX Road visibility test results are given graphically in a form of visibility envelope, which represents the border of visibility field (Fig. 5), and numerically by lengths of road sections on which required sight distance wasn't achieved.

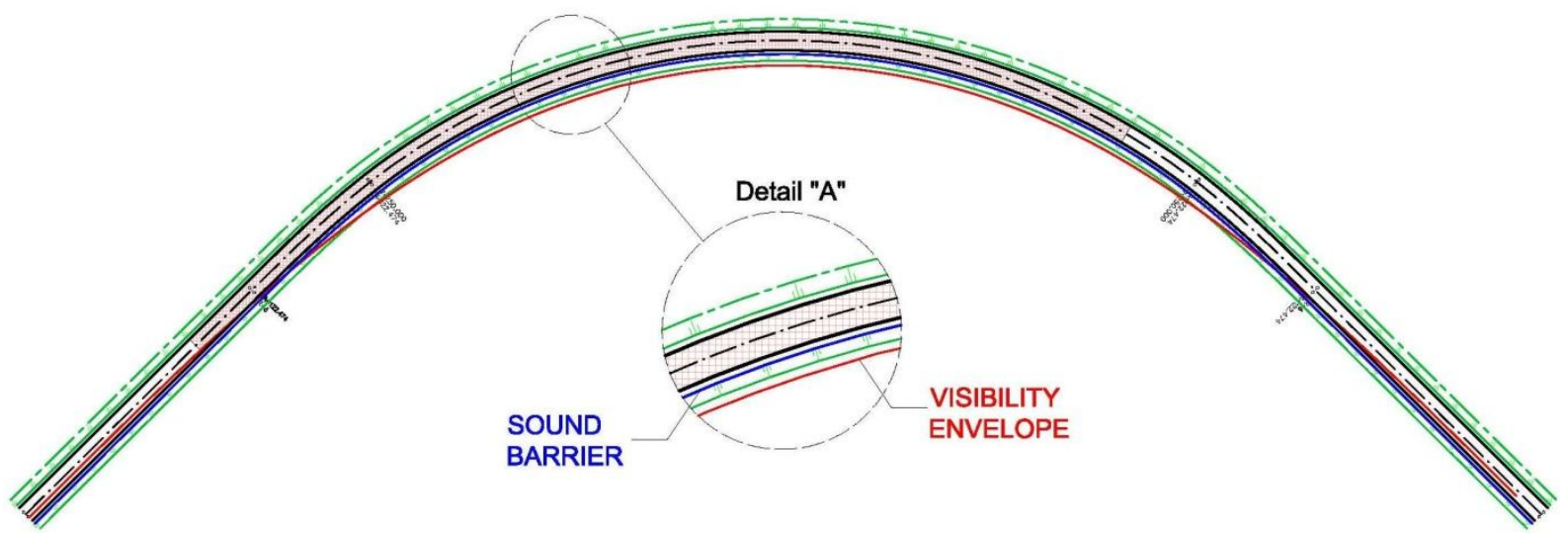

Figure 5. Visibility test results for road with deflection angle $90^{\circ}$

With barrier placed at minimum distance from carriageway edge, stopping sight distance was not achieved in any of eight testing models. Visibility tests also showed that length of road sections with unfulfilled sight distance grow with increasing deflection angle value (Table 2, Fig. 6). Additionally, maximum displacements of barrier for every examined deflection angle are smaller than values defined by regulations $(4.1 \mathrm{~m})$. 
ROMANIAN JOURNAL

OF TRANSPORT INFRASTRUCTURE

Tamara Džambas, Saša Ahac, Vesna Dragčević

The influence of visibility conditions in horizontal road curves on the efficiency of noise protection barriers

Table 2. Visibility test results

\begin{tabular}{|c|c|c|}
\hline $\begin{array}{c}\text { Deflection } \\
\text { angle }\left[{ }^{\circ} \mathbf{]}\right.\end{array}$ & $\begin{array}{c}\text { Maximum displacement } \\
\text { of barrier [m] }\end{array}$ & $\begin{array}{c}\text { Length of road sections with } \\
\text { unfulfilled sight distance [m] }\end{array}$ \\
\hline 20 & 2.56 & 80 \\
\hline 30 & 3.71 & 130 \\
\hline 40 & 3.97 & 170 \\
\hline 50 & 4.05 & 220 \\
\hline 60 & 4.06 & 270 \\
\hline 70 & 4.02 & 310 \\
\hline 80 & 4.02 & 350 \\
\hline 90 & 4.00 & 390 \\
\hline
\end{tabular}

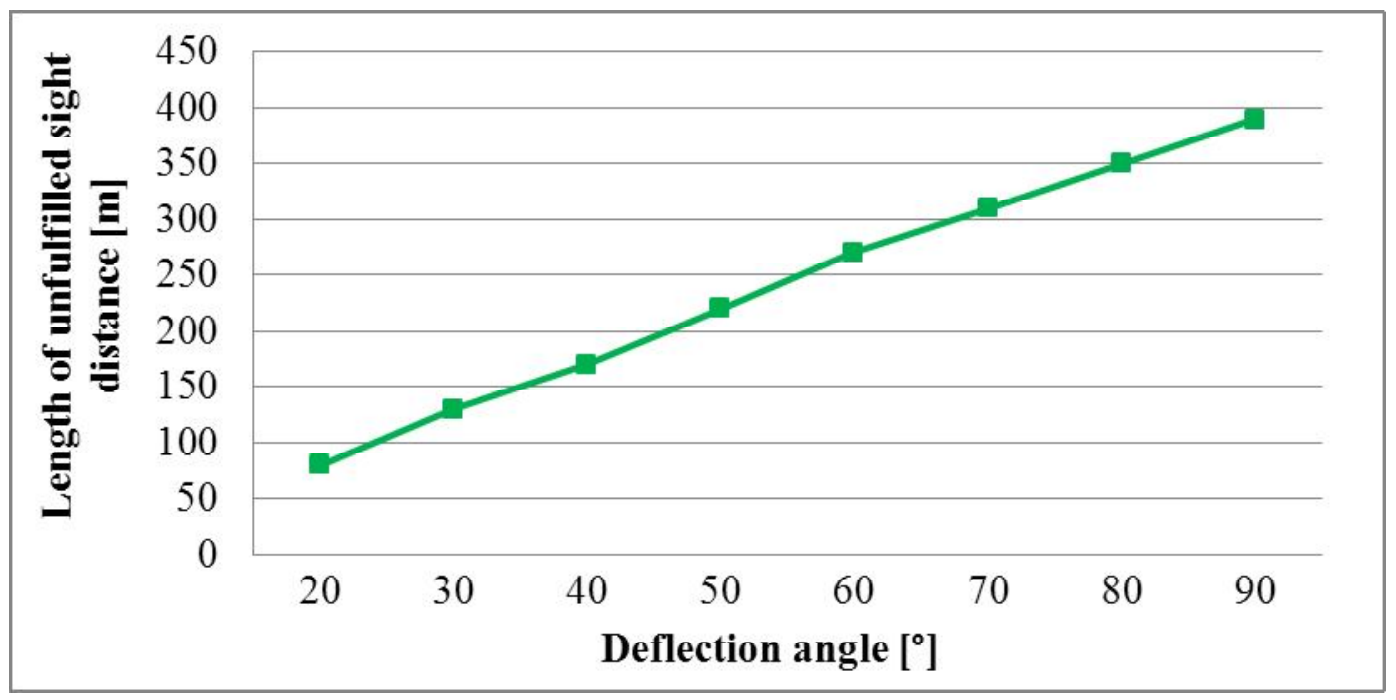

Figure 6. Relation visibility-deflection angle value

\section{NOISE BARRIER EFFICIENCY TESTING}

Barrier dimensioning was carried out by optimization procedure through specialized noise prediction software LimA, using static noise calculation method RLS 90, as described below.

\subsection{Input data for barrier optimization}

Traffic noise level calculation model consists of digital 3D terrain model and acoustic data about noise source, noise spreading direction and barrier characteristics. 3D terrain model in this research was composed of digital relief model and digital road model. 
In order to examine the influence of visibility conditions in horizontal road curves on the efficiency of noise protection barriers, two different digital terrain models were created. First model consists of eight road models with same cross sections used for visibility testing in MX Road (Fig. 3). In second model, in order to take into the account the widening of road bank needed to achieve sufficient visibility on analysed horizontal curves, all road side banks were expanded to visibility envelopes. According to this, two groups of barrier optimization procedures were conducted: for barrier placed at minimum distance from carriageway edge $(1.5 \mathrm{~m})$, and for barrier placed on the outside edge of the widened road bank (Fig. 7).

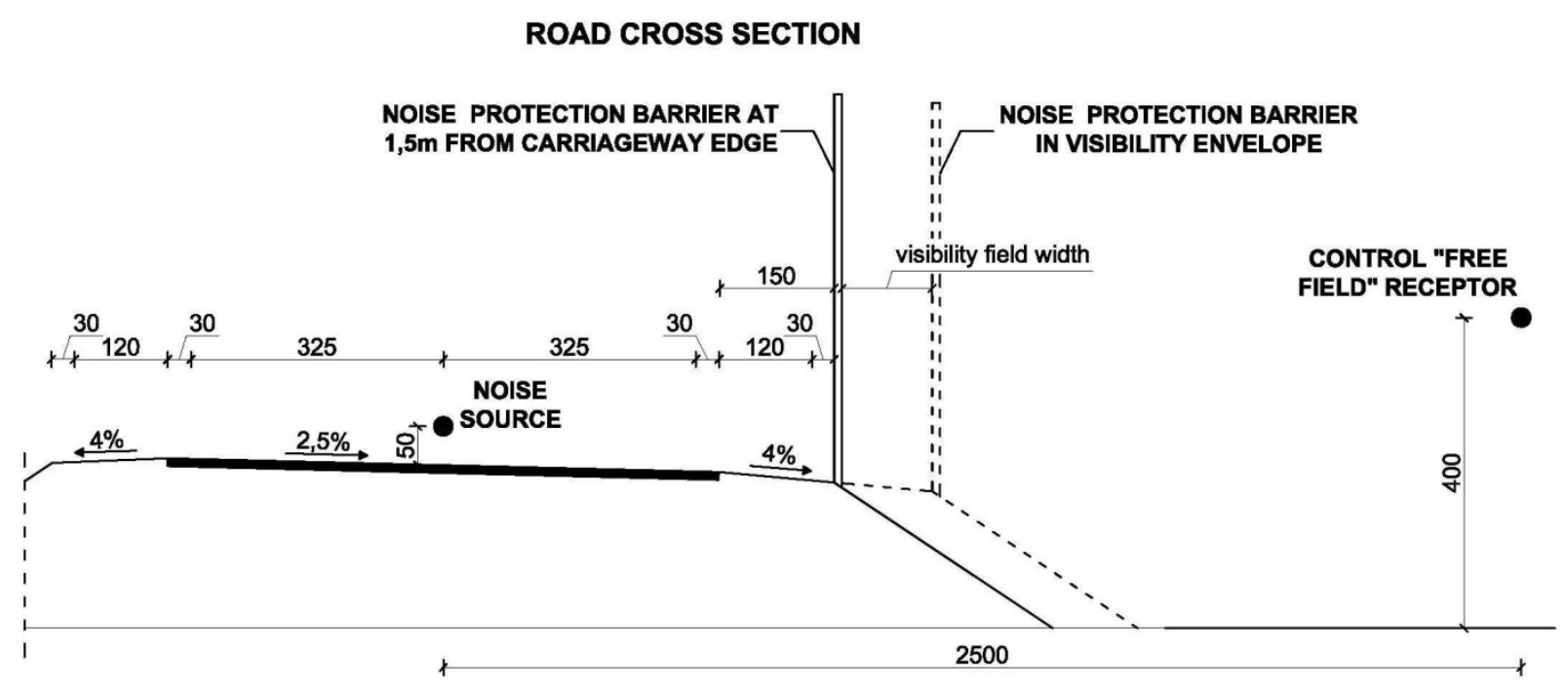

Figure 7. Models used for testing of barriers efficiency

For all road models following input data was applied. Noise source is defined as line source positioned $0.5 \mathrm{~m}$ above driving surface in road axis. Road is described as regional with AADT value $7000,10 \%$ of heavy vehicles and driving speed of $80 \mathrm{~km} / \mathrm{h}$.

Determination of barrier dimensions by optimization procedure is performed by locating of control receptor and by setting barrier parameters and initial location. In this research, control receptor was positioned at 25 meters from noise source at the inner side of a curve (Fig. 7). According to [5], noise levels used to optimize noise barriers are: $65 \mathrm{~dB}(\mathrm{~A})$ for day and evening period (day 07-19 h, evening 19-23 h) and 50 dB(A) for night period (night 23-07 h). Barrier was erected $200 \mathrm{~m}$ along the road at a distance of $1.5 \mathrm{~m}$ from carriageway edge i.e. in visibility envelope. It consists of $4 \mathrm{~m}$ long and up to $5 \mathrm{~m}$ 
high elements sorted in $20 \mathrm{~m}$ long groups of same height (Fig. 8). Height increment between groups is $0.5 \mathrm{~m}$.

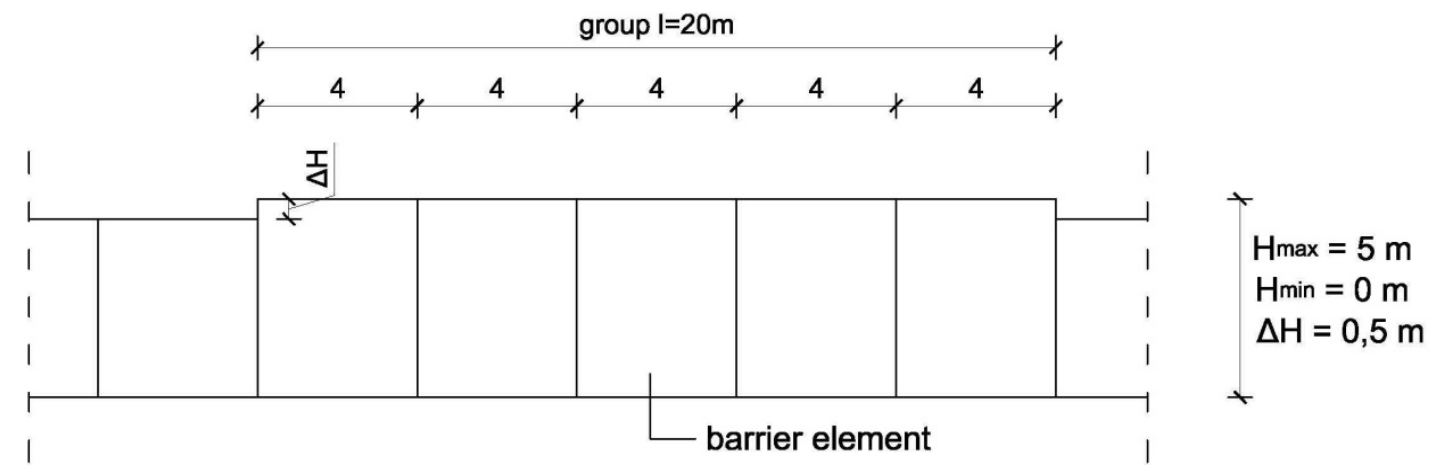

Figure 8. Input parameters for barrier optimization procedure

\subsection{Test results}

Barrier height and length values, necessary to reduce noise levels in receptor to prescribed value, are obtained by optimization procedure. Additionally, optimized barrier areas are calculated, as shown in Table 3. A1 are dimensions of barriers placed at minimum distance from carriageway edge, and A2 are dimensions of barriers placed in visibility envelope. Test results indicate that some dimensions increased, some decreased and some stayed unchanged due to distancing from a road. Maximum difference between areas A1 and A2 is approximately $30 \mathrm{~m}^{2}$. Test results also showed that changes in barrier dimensions are not associated with deflection angle values (Fig. 10).

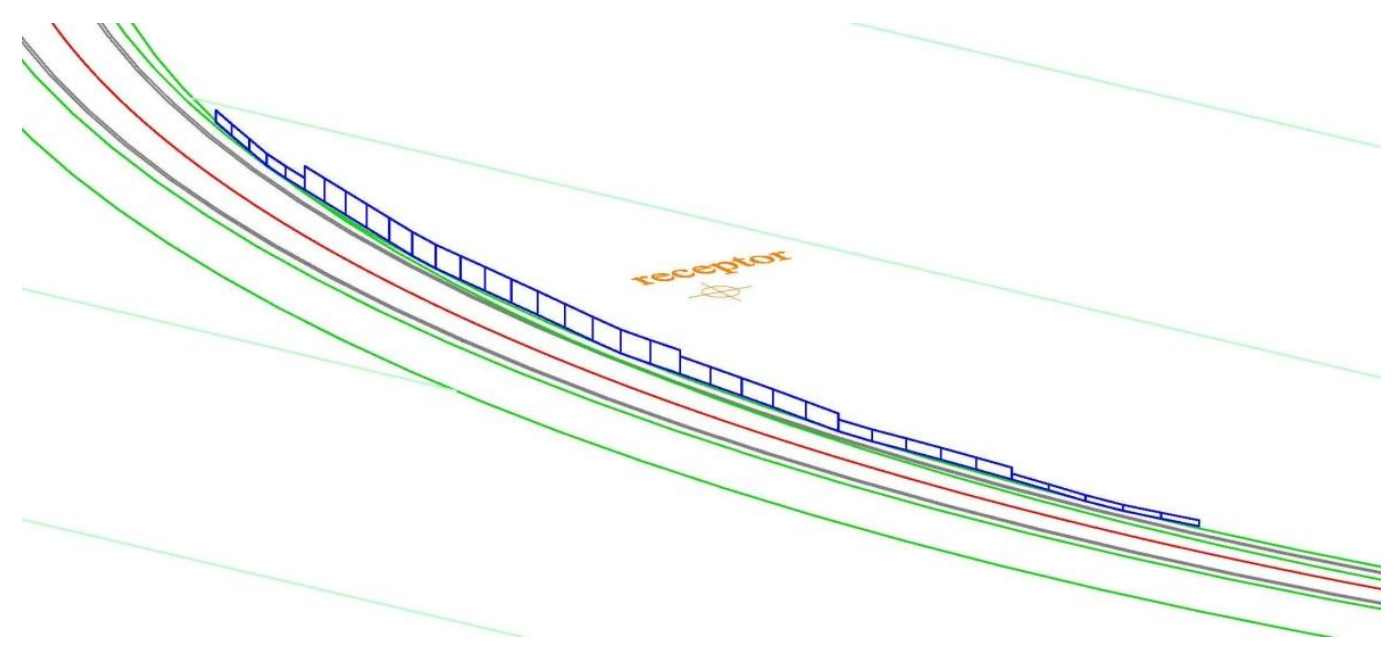

Figure 9. Graphic result of barrier optimisation procedure 
ROMANIAN JOURNAL

Table 3. Comparison of barrier optimization results

\begin{tabular}{|c|c|c|c|}
\hline Deflection angle $\left[{ }^{\circ}\right]$ & $\mathbf{A 1}\left[\mathbf{m}^{\mathbf{}}\right]$ & $\left.\mathbf{A 2} \mathbf{~ m}^{\mathbf{}}\right]$ & $\mathbf{\Delta A}\left[\mathbf{m}^{\mathbf{}}\right]$ \\
\hline 20 & 220 & 230 & -10 \\
\hline 30 & 190 & 210 & -20 \\
\hline 40 & 190 & 180 & 10 \\
\hline 50 & 208 & 180 & 28 \\
\hline 60 & 190 & 190 & 0 \\
\hline 70 & 196 & 210 & -14 \\
\hline 80 & 180 & 180 & 0 \\
\hline 90 & 200 & 180 & 20 \\
\hline \multicolumn{2}{|l}{} \\
\hline
\end{tabular}

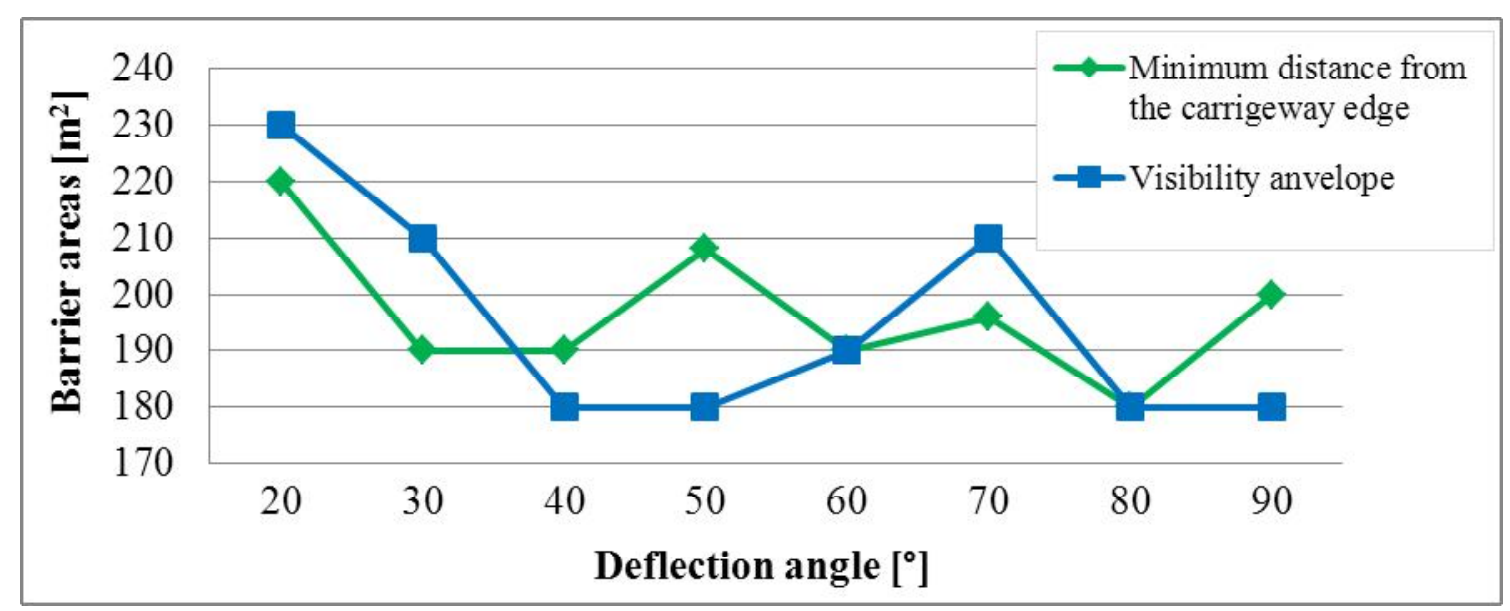

Figure 10. Relation barrier dimensions-deflection angle value

\section{CONCLUSIONS}

Considering the fact that visibility is one of the most essential factors of road traffic safety, stopping sight distance at all road sections must be ensured; this also applies to sections with noise protection barriers. Lack of visibility is not an issue at new roads where noise barriers are planned and erected in accordance with road project that includes visibility testing and determination of land expropriation width. Problems can emerge at the existing roads, especially those placed in low profile embankments, where area for road construction is already redeemed and barrier placement to the outer edge of the visibility field is often not possible.

The main goal of the research presented in this paper was to establish if required stopping sight distance in road curves with minimum radius can be achieved when noise protection barrier is placed at minimum distance from carriageway edge. Another goal was to determine whether the barrier 
displacement to the outer edge of the visibility field on the inside of a curve, that should be conducted in order to achieve minimum required visibility, has any influence on its optimized dimensions.

Visibility test results showed that required stopping sight distance with barrier placed at minimum distance from carriageway edge isn't achieved on any of eight testing models; and secondly that visibility is reduced with increasing deflection angle value. Barrier optimization results showed that barrier distancing from carriageway edge has minor impact on its optimized dimensions.

Based on these results it can be concluded that ensuring the visibility in horizontal road curves has negligible influence on the efficiency of noise protection barriers i.e. on barrier construction costs. If barrier is placed at minimum distance from carriageway edge (mostly due to described problem with existing roads), additional visibility testing must be carried out and driving speed should be limited to values where required stopping sight distance is ensured. In accordance with that, driving speed presumed in this research should be decreased for approximately $38 \%$. Tests performed in this research should be carried out on a larger number of models with different input parameters in order to show whether conclusions obtained in this paper can be applicable to all cases, or just on particular testing model.

\section{REFERNCES}

[1]. LJ. ŠIMUNOVIĆ: „Road visibility”, Faculty of Transport and Traffic Engineering, Zagreb, 2011.

[2]. „The Law on Road Traffic Safety”, Official Gazette 74/2011.

[3]. „Regulations about basic terms that public suburban roads and their elements must comply from traffic safety aspects", Official Gazette 110/2001.

[4]. Environmental Protection Department \& Highway Department: „, Guidelines on design of Noise Barriers", Government of the Hong Kong SAR, Second Issue, 2003.

[5]. „Regulations about highest noise levels in territory where people live and work”, Official Gazette 145/2004. 